\title{
The language of medicine and bioethics
}

\author{
Henk ten Have $\cdot$ Bert Gordijn
}

Published online: 31 July 2010

(c) The Author(s) 2010. This article is published with open access at Springerlink.com

The common thread in this issue is language. This is not only a basic tool in health care but also in ethics. One of the fundamental components of health care is communication. Health care provider and health care receiver are continuously interacting. Concerns and complaints are expressed through linguistic means. Recommendations, explanations and reassurances are provided. It is important to understand how language is functioning in these healthcare interactions, because it expresses different kinds of knowledge and values. Øystein Ringstad presents the results of his studies into how concepts are expressed in interactions between patients and practitioners. Language is also important for ethics. Basic notions such as 'autonomy' and 'dignity' are often used but it is not always clear what they exactly mean and how different people interpret them. Hans Morten Haugen analyses the notions of autonomy, dignity and vulnerability. He points out that bioethics is not only an academic discourse using these notions as guiding principles to solve ethical dilemmas. Bioethics also is public debate and policy-making, using the same notions as human rights principles to guide public policies. This interconnection in bioethics between applied ethics and human rights will be elaborated in the Thematic Section in this issue of the journal.

Communication, and therefore language competencies, is especially important in chronic illness when the autonomy of the person is more and more under threat. In such conditions, as shown in the article of Moser et al., patients will need responsive relationships with support and shared

H. ten Have $(\bowtie) \cdot$ B. Gordijn

Center for Healthcare Ethics, Duquesne University, Fisher Hall

33, 600 Forbes Avenue, Pittsburgh, PA 15282, USA

e-mail: tenhaveh@duq.edu responsibility. Individual autonomy is also a basic notion in the field of acute care. It is particularly problematic in the field of parental living kidney donation. How can there be a free and informed choice when parents are strongly committed to provide the best for their children? This moral imperative is demonstrated in the study of Kristin Zeiler and others. Narrative analysis of parents' stories clearly shows that parents should donate, so that the language of free choice is not appropriate anymore. For parents, it is 'natural' to donate since parents have the obligation to put the needs of their child above everything else. Donating is a matter of non-choice. These findings complicate the discourse of autonomy that usually underlies the ethical justification of living donation. From a Hippocratic perspective living donation is already difficult to justify (since potential harm to the donor cannot be avoided).

Finally, Kasper Lipper-Rasmussen and Sigurd Lauridsen discuss the issue of justice and allocation of healthcare resources. They focus on indirect, non-health effects of allocation, for example on the quality of life within society or the productivity of the workforce. They examine the principal objections against counting these effects. They conclude that indirect, non-health effects should be taken into account since health needs are related to other urgent needs such as employment, care and basic education.

The special section in this issue, "Medicine, Ethics and Human Rights" has been edited by Andreas Frewer and Markus Rothhaar. The contributions have been prepared by the Forum for Medicine and Human Rights in the University of Erlangen-Nuremberg. The city of Nuremberg considers itself as the 'City of Human Rights' to undo the dark episodes of the past. It has also been the location of the Nuremberg Code as one of the first international legal documents in the field of medical ethics. The contributions in this section clearly show the new stage in the 
development of global bioethics, with an increasing body of documents, guidelines, publications at the level of international law. The language of human rights is becoming the new language of bioethics.
Open Access This article is distributed under the terms of the Creative Commons Attribution Noncommercial License which permits any noncommercial use, distribution, and reproduction in any medium, provided the original author(s) and source are credited. 